\title{
Rumex acetosa modulates platelet function and inhibits thrombus formation in rats
}

\author{
Dahye Jeong ${ }^{1}$, Muhammad Irfan ${ }^{1}$, Dong-Ha Lee², Seung-Bok Hong ${ }^{3}$, Jae-Wook Oh ${ }^{4}$ and Man Hee Rhee ${ }^{\text {** }}$
}

\begin{abstract}
Background: The Rumex acetosa has been used in medicinal treatment, food technology and phytotherapeutics in Eastern Asia and many other countries. However, its effect on cardiovascular system and antiplatelet activity remained to be known. In this study, we examined the antiplatelet activity of $R$. acetosa in detailed manner to understand underlying mechanism.

Methods: To study this, whole blood was obtained from male Sprague Dawley (SD) rats and aggregation of washed platelets measured using light transmission aggregometry. Intracellular calcium ion concentration $\left(\left[\mathrm{Ca}^{2+}\right]_{i}\right)$ was measured using Fura-2/AM while ATP release evaluated by luminometer. Activation of integrin $a_{\| b} \beta_{3}$ analyzed by flow cytometry and clot retraction. Furthermore, we studied the signaling pathways mediated by $R$. acetosa extract by western blot analysis.

Results: $R$. acetosa extract markedly inhibited collagen-induced platelet aggregation and ATP release in a dosedependent manner. It also suppressed $\left[\mathrm{Ca}^{2+}\right]_{i}$ mobilization, integrin $\mathrm{a}_{\| \mathrm{b}} \beta_{3}$ activation and clot retraction. The extract significantly attenuated phosphorylation of the MAPK pathway (i.e., ERK1/2, JNK), MKK4, PI3K/Akt, and Src family kinase.

Conclusion: Taken together, this data suggests that $R$. acetosa extract exhibits anti-platelet activity via modulating MAPK, PI3K/Akt pathways, and integrin $a_{\| b} \beta_{3}$-mediated inside-out and outside-in signaling, and it may protect against the development of platelet-related cardiovascular diseases.
\end{abstract}

Keywords: Antiplatelet agent, Integrin $a_{\| b} \beta_{3}$, MAPK, Platelets, Rumex acetosa, Thrombosis

\section{Background}

World Health Organization (WHO) disclosed (EURO/ 03/06) that cardiovascular disease (CVD) reveal the highest mortality among all diseases in western world. WHO has also stated that CVD accounted for 30\% of all the deaths that occurred in 2005. In Europe, CVD remains the primary cause of death accounting for $42 \%$ of mortalities in men and $52 \%$ of deaths in women [1-3]. Coronary heart disease alone caused almost one in every seven deaths and heart failure caused one in nine deaths in the United States in 2013 [4]. Atherosclerotic plaque disruption and thrombogenic substrate exposure initiate

\footnotetext{
* Correspondence: rheemh@knu.ac.kr

'Laboratory of Veterinary Physiology and Cell Signaling, College of Veterinary Medicine, Kyungpook National University, Daegu 41566, Republic of Korea Full list of author information is available at the end of the article
}

platelet activation and aggregation, triggering coagulation cascade which lead to thrombus formation. Acute myocardial infarction and sudden death are the main clinical manifestations of atherosclerosis [5, 6]. For the last decades, antiplatelet drugs have been developed to prevent cardiovascular disease. However, these drugs have serious side effects; in particular, the side effects of aspirin are gastric ulcers and bleeding, and clopidogrel sometimes results in aplastic anemia and thrombocytopenic purpura [7]. Beside treatment of cardiovascular risk factors and use of antithrombotic agents there is considerable interest in traditional remedies and use of natural food products in prevention of CVD [8-12].

In our effort to discover complementary materials, we found Rumex acetosa L, a natural product known to have ethnomedicinal properties. Plants were vital much 
before the human civilization. Specially, they have been used to intake as well as traditional medicine to improve health for years. The Rumex (dock) species have been used in medical treatment for many centuries owing to their astringent, spasmolytic, antithrombotic and cholagogic activity $[13,14]$. $R$. acetosa is a perennial plant distributed in eastern Asia, Europe, and America [15] and the plant often called 'Sorrel', have been used within food technology and as phytotherapeutic materials in Korea and Japan [16]. The phytochemical components of $R$. acetosa extract have recently been identified to be monomeric flavan-3-ols (catechin, epicatechin, and epicatechin-3-O-gallate), A- and B-type procyanidins, and propelargonidins (15 dimers, 7 trimers, 2 tetramers) $[17,18]$. This plant's medicinal properties are related to its tannin content and are useful for the treatment of various ailments [19]. Previous studies reported that $R$. acetosa possessed antioxidant $[19,20]$, anti-hypertensive [21], antiviral, [22] and anticancer effects [23]. However, information on the antiplatelet effects of $R$. acetosa $\mathrm{L}$ extract remained to be discovered. Therefore, we investigated in vitro anti-platelet effect of $R$. acetosa extract and discovered underlying mechanism and signaling pathway in rat platelets (Fig. 1).

\section{Methods}

\section{Chemicals and reagents}

Thrombin and Collagen (Native collagen fibrils, type I, from equine tendons) were procured from Chrono-Log Co. (Havertown, PA, USA). ATP assay kit was acquired from Biomedical Research Service Center (Buffalo, NY, USA), while Fibrinogen Alexa Fluor ${ }^{\circ} 488$ conjugate was acquired from Molecular Probes (Eugene, OR, USA). Fura-2/AM and dimethyl sulfoxide (DMSO) were obtained from Sigma Chemical Co. (St. Louis, MO, USA). Antibodies against ERK (p44/42), phospho-ERK (p44/42), JNK, phospho-JNK, PI3K (p85/p55), phospho-PI3K (p85/p55), Akt (Ser473), phosphoAkt (Ser473), MKK4, phosphor-MKK4, Src (Tyr416), and phospho-Src (Tyr416) were obtained from Cell signaling
(Beverly, MA, USA). Water was acquired from J. T. Baker (Phillipsburg, NJ, USA). All chemicals were of reagent grade.

\section{Procurement of plant material and extract preparation}

Whole dried plant of $R$. acetosa was collected from Rural Development Administration (RDA) in Suwon city. Dr. Jeong-Hoon Lee and Dr. Seung-Eun Lee at RDA undertook the formal identification of plant materials on the basis of botanical characteristics. A voucher specimen of the plant material has been deposited in National Institute of Horticultural and Herbal Science (NIHHS), Eumseong, Republic of Korea, with Voucher ID (NIHHS 2012-026).

The powder $(100 \mathrm{~g})$ of $R$. acetosa plant was extracted with methanol in accelerated solvent extraction system (Dionex, USA) at $50{ }^{\circ} \mathrm{C}$, and evaporated in rotary evaporator (N-1000, Eyela, Japan). Finally, crude extract was obtained and stored at $-30^{\circ} \mathrm{C}$ for further use in experiments.

\section{Animals}

Male Sprague Dawley (SD) rats (7 weeks old, 240-250 g) were purchased from Orient Co. (Seoul, Korea). Rats were acclimatized for 1 week before the experiments and accommodated in an animal room with a 12/12-h light/ dark cycle at a temperature and humidity of $22 \pm 1{ }^{\circ} \mathrm{C}$ and $50 \pm 10 \%$, respectively. All experiments were carried out in accordance with the National Institutes of Health $(\mathrm{NIH})$ guidelines and protocols approved by the Ethics Committee of the College of Veterinary Medicine, Kyungpook National University (Daegu, Korea); and later, rats were euthanized by an overdose of $5 \%$ isoflurane as previously described [24]. Isoflurane exposure was continued after $1 \mathrm{~min}$ of breathing stoppage, followed by cervical dislocation for confirmation of euthanasia.

\section{Platelet preparation}

Preparation of washed platelets was conducted as previously described [25]. Briefly, whole blood was collected from rats via heart puncture and anticoagulated with

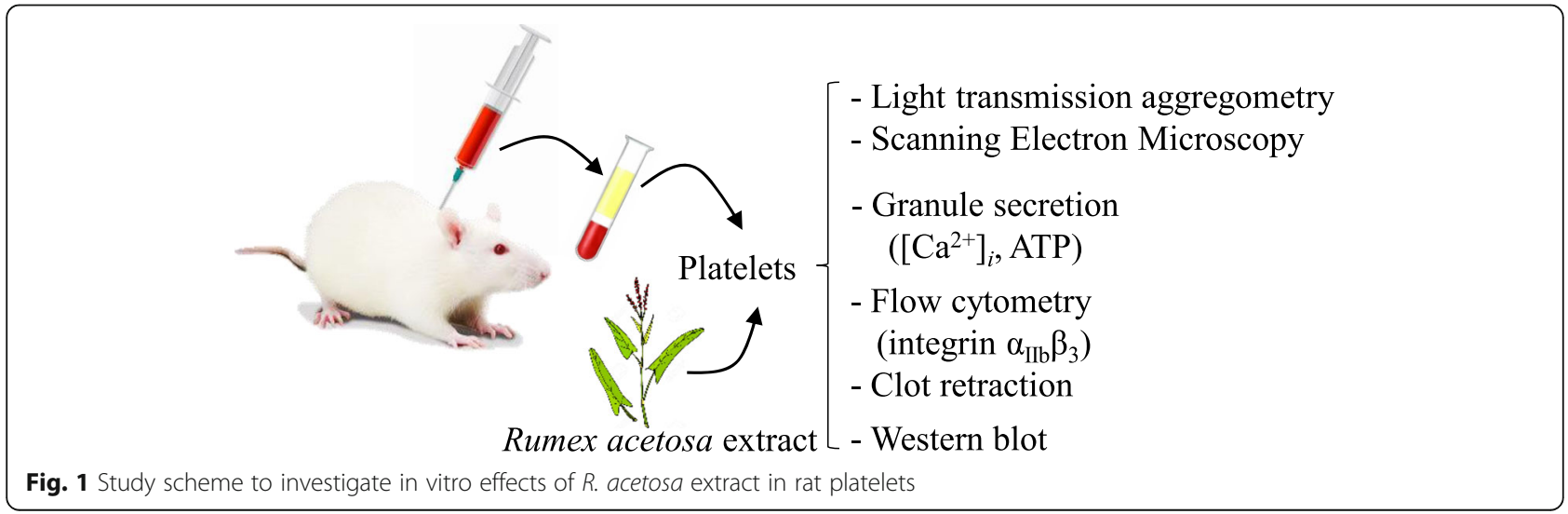


ACD solution. Firstly, to obtain PRP, anticoagulated blood was centrifuged at $170 \times g$ for $7 \mathrm{~min}$. Remaining RBC's were removed by centrifuging the PRP at $120 \times g$ for $7 \mathrm{~min}$. Subsequently, washed platelets were isolated by centrifuging the PRP at $350 \times g$ for $7 \mathrm{~min}$. Platelets were resuspended in Tyrode's buffer $(137 \mathrm{mM} \mathrm{NaCl}, 12$ $\mathrm{mM} \mathrm{NaHCO} 3,5.5 \mathrm{mM}$ glucose, $2 \mathrm{mM} \mathrm{KCl}, 1 \mathrm{mM}$ $\mathrm{MgCl}_{2}$, and $0.3 \mathrm{mM} \mathrm{NaHPO}$, $\mathrm{pH}$ 7.4) and platelet concentration was adjusted at $3 \times 10^{8}$ cells $/ \mathrm{mL}$. All the platelet preparation procedure was performed at room temperature (i.e., $23 \pm 2^{\circ} \mathrm{C}$ ).

\section{Platelet aggregation assay and scanning electron microscopy analysis}

Platelet aggregation assay was performed as previously described [26]. Aggregation was assessed by light transmission in an aggregometer (Chronolog, Havertown, PA, USA). Briefly, washed platelets were pre-incubated either with vehicle or different concentration of $R$. acetosa extract for $2 \mathrm{~min}$ at $37^{\circ} \mathrm{C}$, and then aggregation was induced with collagen for $5 \mathrm{~min}$ under continuous stirring condition. The vehicle concentration was held at less than $0.1 \%$.

The scanning electron microscopy (SEM) analysis was performed using a Field Emission Scanning Electron Microscope (SU8220, Hitachi, Japan). After the termination of platelet aggregation, the washed platelets were fixed in $0.5 \%$ paraformaldehyde and Osmium tetroxide, dehydrated by ascending concentrations of ethanol, and freeze-dried and analyzed by the SEM.

\section{$\left[\mathrm{Ca}^{2+}\right]_{i}$ measurement}

The intracellular calcium mobilization $\left(\left[\mathrm{Ca}^{2+}\right]_{i}\right)$ was assessed with Fura-2/AM [27], and Fura-2 fluorescence in the cytosol was quantified with the spectrofluorometer as previously described by Schaeffer and Blaustein [28] using the following formula: $\left[\mathrm{Ca}^{2+}\right]_{i} 224$ $\mathrm{nM} \times\left(F-F_{\text {min }}\right) /\left(F_{\text {max }}-F\right)$, where $224 \mathrm{nM}$ is the dissociation constant of the Fura-2-Ca ${ }^{2+}$ complex, and $F_{\text {min }}$ and $F_{\max }$ represent the fluorescence intensity levels at very
$\mathbf{A}$

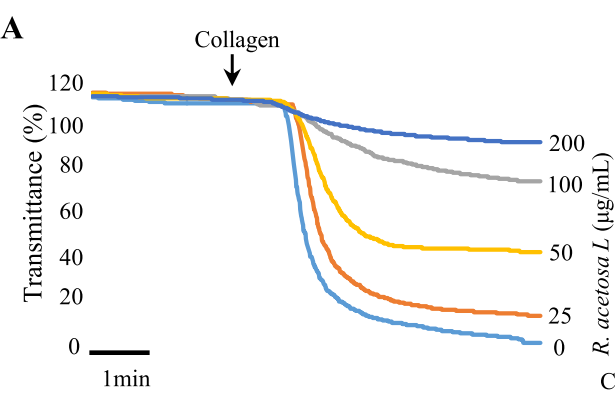

C
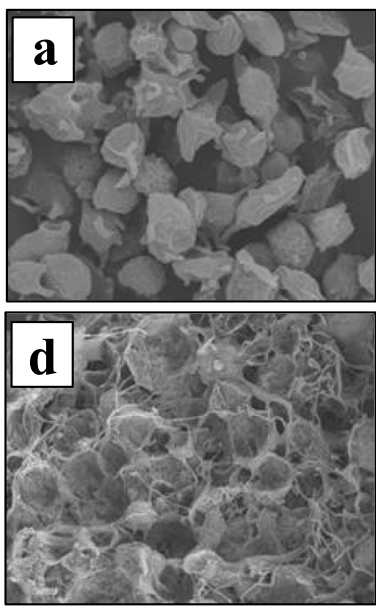

B
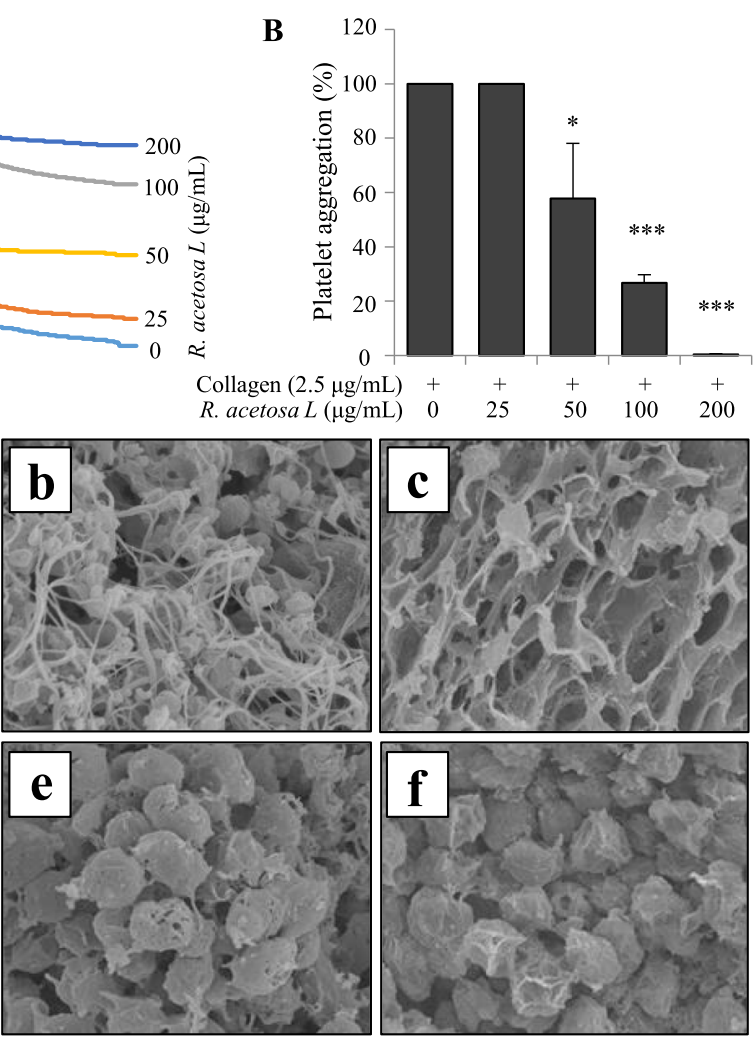

Fig. 2 The inhibitory effect of R. acetosa extract on collagen-induced platelet aggregation. Platelets were pre-incubated with or without $R$. acetosa extract $(25-200 \mu \mathrm{g} / \mathrm{mL})$ in the presence of $1 \mathrm{mM} \mathrm{CaCl}_{2}$ for 2 min at $37^{\circ} \mathrm{C}$ with stirring and stimulated with collagen $(2.5 \mu \mathrm{g} / \mathrm{mL})$ for $5 \mathrm{~min}$ (a-c). After the aggregation reaction was terminated, platelet aggregation was quantified and expressed as percentage. $\mathbf{c}$ Representative scanning electron microscopy images of platelets treated with various concentrations of extract or vehicle [Resting state (a), vehicle (b), $R$. acetosa extract $25 \mu \mathrm{g} / \mathrm{mL}(\mathbf{c}), 50 \mu \mathrm{g} / \mathrm{mL}(\mathbf{d}), 100 \mu \mathrm{g} / \mathrm{mL}(\mathbf{e})$, or $200 \mu \mathrm{g} / \mathrm{mL}(\mathbf{f})]$. Each graph shows the mean \pm SD of at least four independent experiments. ${ }^{*} P<$ 0.05 and ${ }^{* *} P<0.001$ compared to the agonist control 
low and very high $\mathrm{Ca}^{2+}$ concentrations, respectively. Here, $F_{\min }$ and $F_{\max }$ is the fluorescence intensity of Fura-2- $\mathrm{Ca}^{2+}$ complex measured at $510 \mathrm{~nm}$ when platelet suspension treated with $20 \mathrm{mM}$ Tris/3 mM of EGTA and $1 \mathrm{mM}$ of $\mathrm{CaCl}_{2}$ solubilized with Triton X-100 $(0.1 \%)$, respectively; while $F$ denotes the intensity when suspension is treated with collagen in presence or absence of $R$. acetosa $\mathrm{L}$ extract along $1 \mathrm{mM} \mathrm{CaCl}_{2}$.

\section{ATP release assay}

Platelets were pre-incubated either with vehicle or different concentration of $R$. acetosa extract in the presence of $1 \mathrm{mM} \mathrm{CaCl} 2$ at $37^{\circ} \mathrm{C}$ for $2 \mathrm{~min}$ prior to stimulation with collagen $(2.5 \mu \mathrm{g} / \mathrm{mL})$ for 5 min under continuous stirring condition. Reaction was stopped and suspension was centrifuged at high speed to collect supernatant. ATP concentration was assessed in luminometer (GloMax20/20; Promega, Madison, USA) using an ATP assay kit according to manufacturer's protocol.

\section{Measurement of fibrinogen binding to integrin $\alpha_{11 b} \beta_{3}$} Fibrinogen Alexa Fluor ${ }^{\circ} 488$ conjugate binding to integrin $\alpha_{\mathrm{II}} \beta_{3}$ on platelets was assessed by flow cytometry as previously described [29]. Briefly, washed platelets were pre-incubated either with vehicle or different concentrations of $R$. acetosa extract along with $0.2 \mathrm{mM} \mathrm{CaCl}_{2}$ for $2 \mathrm{~min}$. The platelets were stimulated with collagen for 5 min, following incubation with fibrinogen Alexa Fluor ${ }^{\circ}$ $488(20 \mu \mathrm{g} / \mathrm{mL})$ for $5 \mathrm{~min}$ at room temperature, and then fixed with $0.5 \%$ paraformaldehyde for $30 \mathrm{~min}$ at $4{ }^{\circ} \mathrm{C}$. Alexa Fluor 488-fibrinogen binding to integrin $\alpha_{\mathrm{IIb}} \beta_{3}$ on platelets was quantified by flow cytometry using FACS Aria $^{\text {mat }}$ III flow cytometer ${ }^{\circ}$ (BD Biosciences, San Jose, CA,
USA) while data were analyzed using CellQuest software (BD Immunocytometry Systems, San Jose, CA, USA).

\section{Clot retraction}

The in vitro effect of $R$. acetosa on outside-in signaling through integrin activation was assessed by measuring clot retraction as previously described [29]. PRP $(250 \mu \mathrm{L})$ was incubated with vehicle, $R$. acetosa extract or Y27632 (Rock inhibitor) for $2 \mathrm{~min}$, following addition of RBC's $(5 \mu \mathrm{L})$ and Tyrode's buffer to raise the volume up to $1 \mathrm{~mL}$. Clot retraction was initiated by addition of thrombin $(1 \mathrm{U} / \mathrm{mL})$ and observed for $90 \mathrm{~min}$ at room temperature. Finally, clot weight was measured to assess clot retraction.

\section{Immunoblotting}

Platelets were pre-incubated either with vehicle or different concentration of $R$. acetosa extract in the presence of $1 \mathrm{mM} \mathrm{CaCl} 2$ at $37^{\circ} \mathrm{C}$ for $2 \mathrm{~min}$ prior to stimulation with collagen $(2.5 \mu \mathrm{g} / \mathrm{mL})$ for $5 \mathrm{~min}$ under continuous stirring condition. Reacting was terminated by adding lysis buffer $[0.125 \mathrm{M}$ Tris- $\mathrm{HCl}, \mathrm{pH}$ $6.8 ; 2 \%$ SDS, $2 \% \beta$-mercaptoethanol, $20 \%$ glycerol, $0.02 \%$ bromophenol blue, $1 \mu \mathrm{g} / \mathrm{mL}$ phenyl methyl sulfonyl fluoride (PMSF), $2 \mu \mathrm{g} / \mathrm{mL}$ aprotinin, $1 \mu \mathrm{g} / \mathrm{mL}$ leupeptin, and $1 \mu \mathrm{g} / \mathrm{mL}$ pepstatin A]. Proteins were quantified by BCA assay (PRO-MEASURE; iNtRON Biotechnology, Seoul, Korea) and total cell proteins $(35 \mu \mathrm{g})$ from the lysates were segregated on 10\% SDSPAGE followed by transferring to polyvinylidene difluoride (PVDF) membranes. The membranes were blocked in 5\% skim milk and then probed with primary and secondary antibodies accordingly in 5\% BSA solution. Finally, antibody binding was pictured
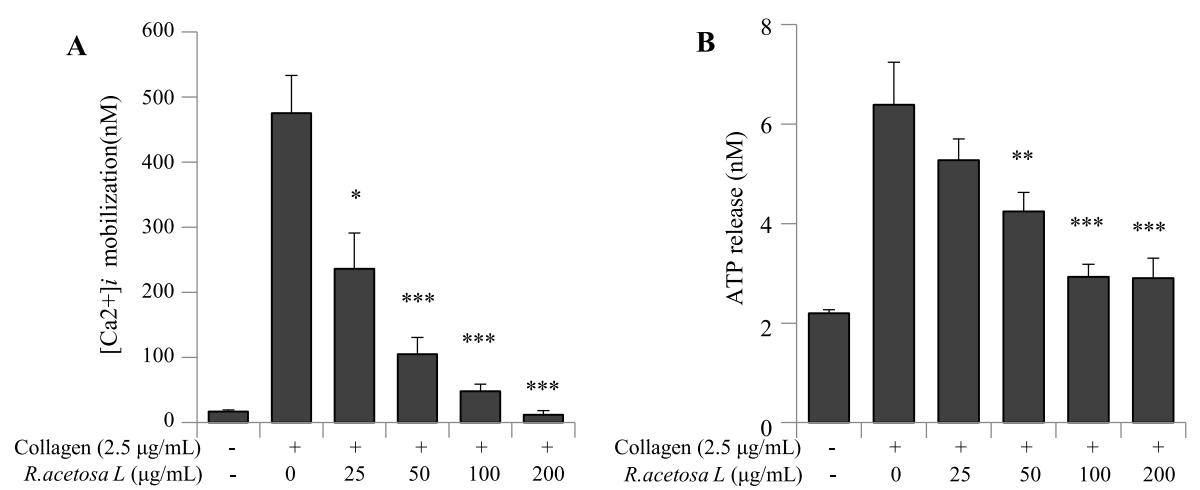

Fig. 3 The inhibitory effect of R. acetosa extract on [Ca2+]i elevation and granule secretion. a Washed platelets were incubated with a calcium fluorophore (5 $\mu \mathrm{M}$, Fura-2/AM), following treatment with different concentrations of $R$. acetosa extract and stimulated with collagen. $\mathbf{b}$ Platelets were pre-incubated with or without $R$. acetosa extract $(25-200 \mu \mathrm{g} / \mathrm{mL})$ in the presence of $1 \mathrm{mM} \mathrm{CaCl} 2$ for 2 min at $37^{\circ} \mathrm{C}$ with stirring and stimulated with collagen for 5 min. Reaction was stopped and ATP release assay was carried out. The results are presented as the mean \pm SD of at least four independent experiments. ${ }^{*} P<0.05,{ }^{*} P<0.01$ and ${ }^{* * *} P<0.001$ versus control 
by enhanced chemiluminescence (iNtRON Biotechnology, Seoul, Korea).

\section{Statistical analysis}

To assess statistical significance among observed differences, the obtained data were analyzed by one-way analysis of variance (ANOVA) followed by post-hoc Dunnett's test (SAS Institute Inc., Cary, NC, USA). The given data are presented as the mean \pm standard deviation (SD). $P$-values of 0.05 or less were considered statistically significant.

\section{Results}

Effect of $R$. acetosa extract on collagen-induced platelet aggregation

Our result showed that $R$. acetosa extract strongly inhibited platelet aggregation induced by collagen in dose dependent manner (Fig. 2a-b). Platelet activation causes granule secretion, shape change and fibrin formation ultimately leading to platelet aggregation. We confirmed the effect of $R$. acetosa $\mathrm{L}$ extract on collagen-induced platelet shape change from inactivated to activated state of platelets under electron

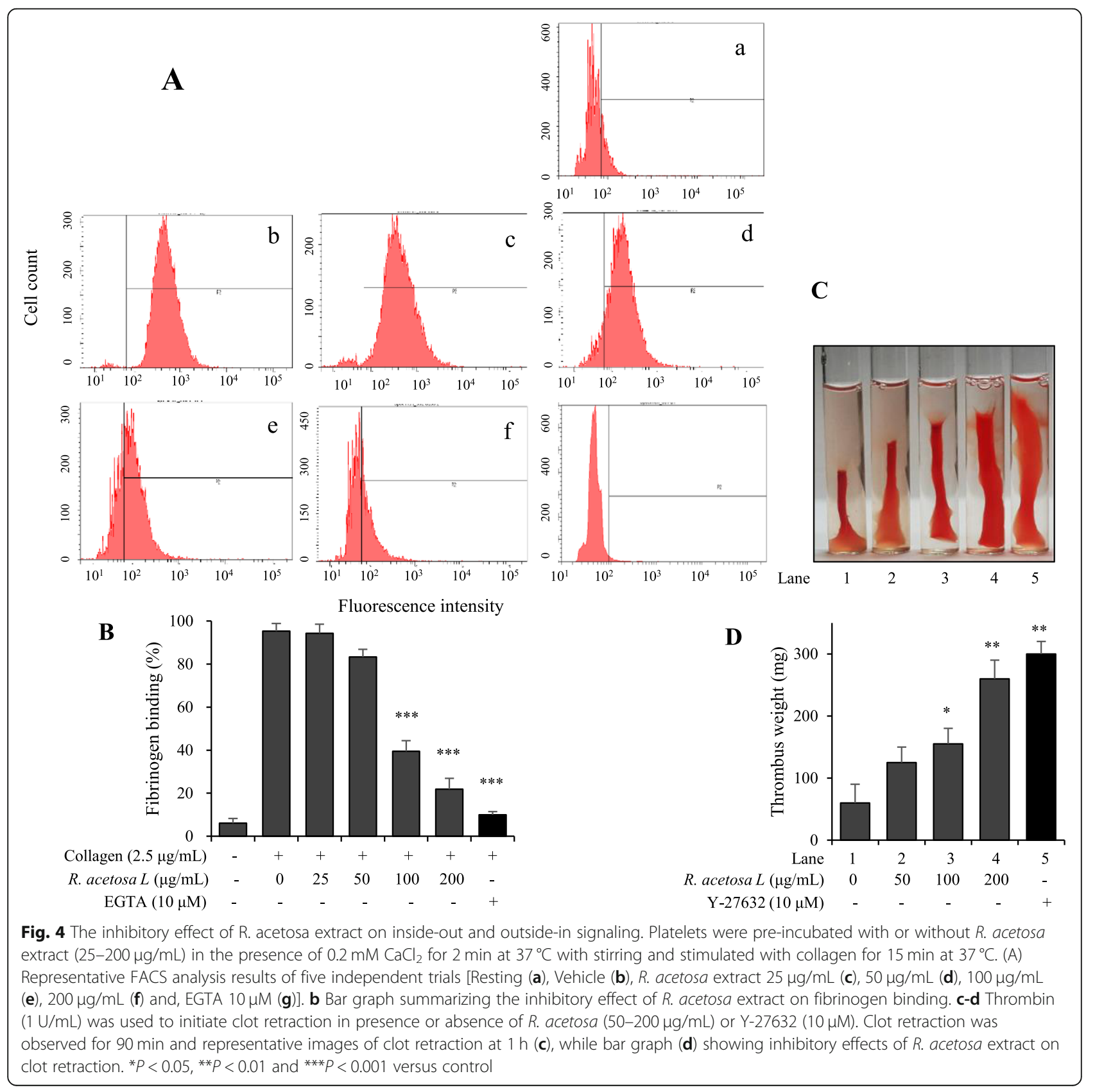


microscope and found dose dependent inhibition of platelet activation and shape change compared with vehicle treated platelets (Fig. 2c).

\section{R. acetos $a$ extract markedly reduced $\left[\mathrm{Ca}^{2+}\right]_{\mathrm{i}}$ mobilization and granule secretion}

We found that pretreatment of platelets with $R$ acetosa extract markedly reduced the elevation in $\left[\mathrm{Ca}^{2+}\right]_{i}$ in collagen stimulated platelets in a dose-dependent manner (Fig. 3a).

Also, collagen strongly increased ATP release from dense granules in vehicle treated platelets by 3-fold in comparison with resting platelets. Our results show that platelets pretreated with $R$. acetosa extract significantly abridged ATP release in a dose-dependent manner (Fig. 3b).

\section{Inhibitory effect of $R$. acetosa extract on inside-out and} outside-in signaling

We found that $R$. acetosa extract reduced affinity of fibrinogen binding to integrin $\alpha_{\mathrm{IIb}} \beta_{3}$ (Fig. 4a-b) and clot retraction via Rho kinase inhibition in a dose-dependent manner (Fig. 4c-d).
Effect of $R$. acetosa extract on MAPK, PI3K/Akt and Src phosphorylation

To explore the underlying mechanism, we further studied the phosphorylation of downstream signaling proteins including MAPK's and MKK4. Our result shown that $R$. acetosa extract reduced the phosphorylation of ERK1/2 and JNK. $R$. acetosa extract also inhibited the phosphorylation of MKK4 which is an upstream signaling molecule of JNK (Fig. 5a).

Our result also revealed that $R$. acetosa extract markedly inhibited collagen-induced PI3K/Akt signaling in a dose-dependent manner. In addition, phosphorylation of Src family kinases plays a role in GPVI-mediated platelet activation and we found that $R$. acetosa extract significantly reduced the activation of Src family kinase (Fig. $5 b)$.

\section{Discussion}

Cardiovascular diseases such as atherosclerosis, thrombosis, and myocardial infarction are the major causes of mortality in the modern world. Platelets play critical roles in hemostasis, thrombosis,

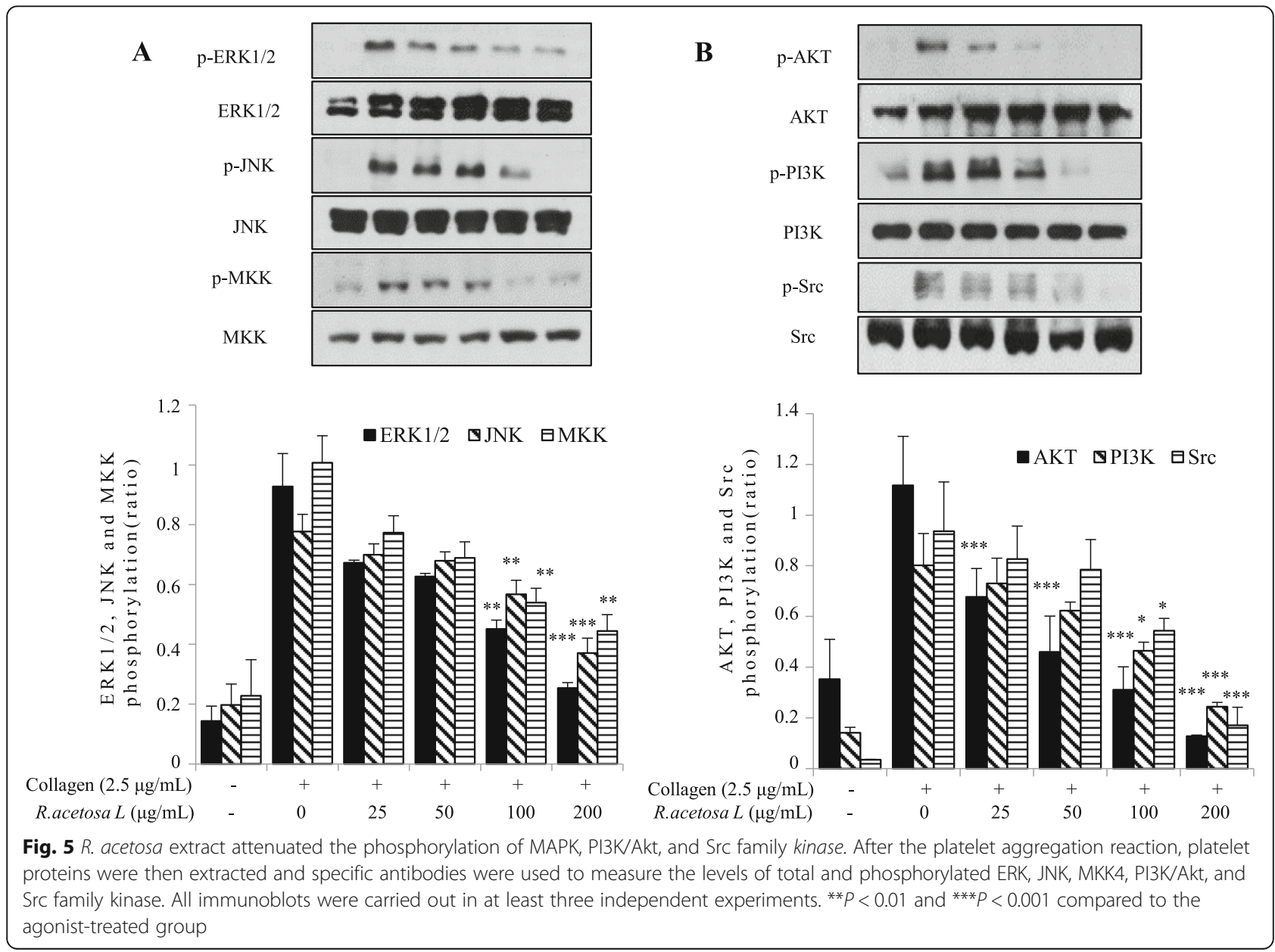


immunity, and inflammation. At the site of vascular injury, platelets are activated by agonists such as collagen, adenosine diphosphate (ADP), and thrombin. These agonists initiate signal transduction through their specific receptors leading to platelet morphologic changes, granule secretion, and aggregation [30]. However, aberrant or over-activation of platelet formation induces a platelet plug and thrombus formation, which can lead to serious ailments such as atherosclerosis. Therefore, the development of antiplatelet agents is a basic goal in cardiovascular research [31].

In the present study, we explored whether $R$. acetosa extract inhibits collagen-stimulated platelet activation and our results showed that $R$. acetosa extract markedly inhibited collagen-stimulated platelet aggregation in a dose-dependent manner. To demonstrate the inhibitory mechanism of $R$. acetosa extract, we further examined downstream signaling components such as intracellular calcium mobilization, granule secretion, integrin signaling, and various proteins phosphorylation. Cytosolic calcium level is known to play a critical role in platelet activation. Increasing calcium levels activates several signaling pathways involved in actin-myosin interaction, protein kinase c (PKC), calmodulin, and calcium-dependent proteases [32]. Our results show that $R$. acetosa extract strongly inhibited the intracellular mobilization of calcium. Intracellular $\mathrm{Ca}^{2+}$ mobilization is also essential for $\alpha$ - and $\delta$ granule secretion [33]. Granule secretion improves platelet activation and recruitment of circulating platelets into injured blood vessels. It is also important for thrombus formation. In this study, we found that treatment with $R$. acetosa extract decreased ATP release from dense granules in collagen-stimulated platelets. Platelets express integrins such as $\alpha_{\mathrm{IIb}} \beta_{3}$ (fibrinogen receptor), $\alpha_{2} \beta_{1}$ (collagen receptor), and $\alpha_{V} \beta_{1}$ (fibronectin receptor). These integrin's regulate signal transduction by various mechanisms. When a specific ligand binds to integrin $\alpha_{\mathrm{IIb}} \beta_{3}$, the fibrinogen receptor changes its conformational structure which enhances affinity to bind with fibrinogen following platelet adhesion and clot retraction [34]. Our data suggests that pretreatment with $R$. acetosa extract dose-dependently blocked fibrinogen binding to integrin $\alpha_{\mathrm{II}} \beta_{3}$ and clot retraction.

Mitogen-activated protein kinases (MAPKs), including ERK1/2 and JNK1, exist in platelets and mediate proliferation, migration, and apoptosis. MAPKs are phosphorylated by several agonists, such as collagen, ADP, and thrombin, and are important for "outside-in" as well as "inside-out signaling" [35]. The PI3K/Akt signaling pathway also is critical for platelet activation and aggregation. Further, PI3Ks are necessary for the tyrosine phosphorylation-based signaling pathways initiated by GPVI or $\alpha_{\mathrm{IIb}} \beta_{3}$ [36]. The results of our study showed that $R$. acetosa extract inhibited phosphorylation of ERK1/2, JNK, and MKK4. Moreover, the PI3K-Akt pathway was also blocked by $R$. acetosa extract. Specific ligand binding to GPVI, the immunoreceptor tyrosinebased activation motif (ITAM) within the FcR $\gamma$ cytoplasmic domain, is a tyrosine moiety phosphorylated by Src family kinases (including Fyn and Lyn). Phosphorylation of Src family kinases is important for GPVI-mediated platelet activation [36]. Our data showed that SFK phosphorylation induced by collagen was significantly decreased by treatment with $R$. acetosa extract. Figure 6 showing a graphical summary of effects of $R$. acetosa extract on platelet intracellular signaling.

Previous reports have suggested that methanolic extract of $R$. acetosa contained several pharmacological compounds such as catechin, epicatechin and epigallocatechin-3-O-gallate [19, 37], while these compounds have been known for their antiplatelet activities [38]. Therefore, antiplatelet effects observed in present study could be attributed to catechin and epicatechin contained in $R$. acetosa extract. We acknowledge that there are some limitations i.e., study could explore in vitro antiplatelet properties of extract in collagenstimulated rat platelets. Future studies may be planned to discover in vivo antiplatelet aspects and unravel other pathways involved in its antithrombotic mechanism.

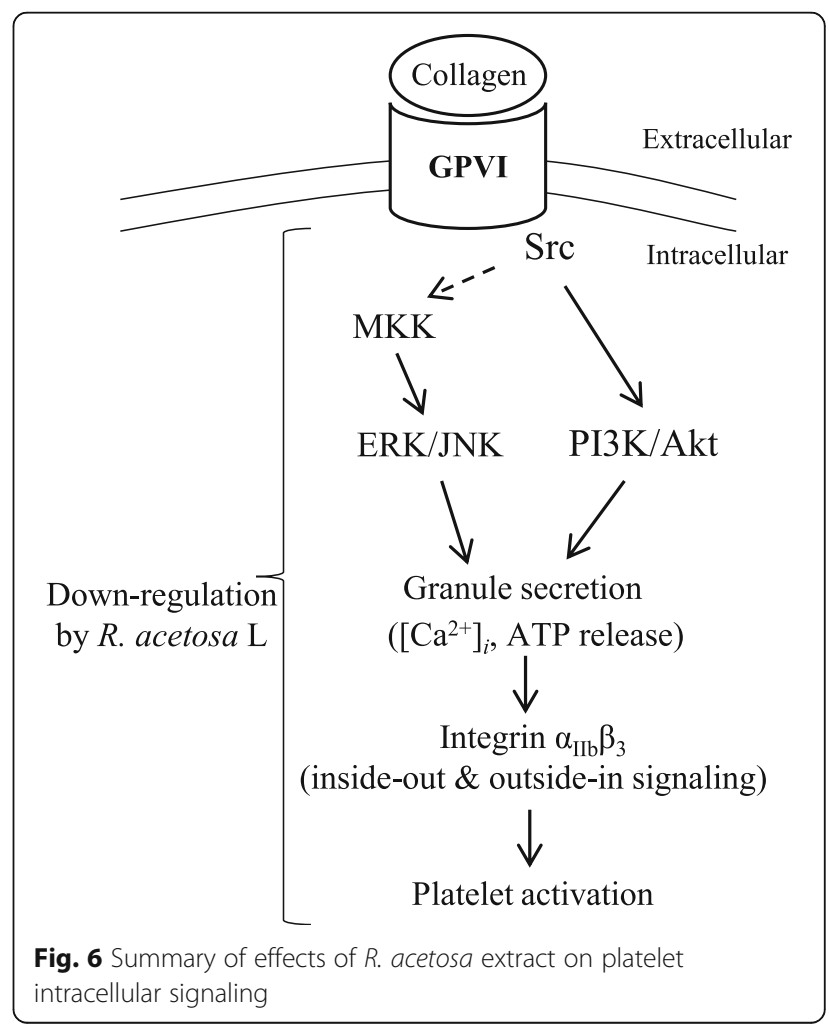




\section{Conclusion}

We conclude that $R$. acetosa extract has potent antiplatelet effects and good candidate in the new era of ethnomedicine against cardiovascular diseases, including atherosclerosis, ischemic stroke, and myocardial infarction. Future studies could explore further in vivo effects of the extract and validate its pharmacological compounds in animals and humans as potential antithrombotic agents.

\section{Abbreviations}

ADP: Adenosine diphosphate; Akt: Protein kinase B; DMSO: Dimethyl sulfoxide; ERK: Extracellular signal-regulated kinase; GPVI: Glycoprotein VI; JNK: c-Jun N-terminal kinase; MAPK: Mitogen-activated protein kinase; MKK4: Mitogen-activated kinase kinase 4; PI3K: Phosphatidylinositol 3-kinases; PRP: Platelet-rich plasma; SFK: Src family kinase

\section{Acknowledgments}

The present data is a part of Master's dissertation of Dahye Jeong.

\section{Authors' contribution}

MHR and DJ designed and conceptualized the study. DJ and MI performed experiments and wrote the manuscript. $\mathrm{Ml}$ critically revised the manuscript. $\mathrm{DHL}, \mathrm{SBH}, \mathrm{JWO}$, and MHR technically assisted in the experiments and preparation of the manuscript. MHR supervised the whole research work. All authors read and approved the final manuscript.

\section{Funding}

This research was supported and funded by the National Research Foundation of Korea (2018R1D1A1A09083797). Funding body did not participate in the design of the study, collection, analysis, interpretation of data or in writing the manuscript.

\section{Availability of data and materials}

The dataset generated during the present study is available upon reasonable request to the author (Prof. Man Hee Rhee).

\section{Ethics approval}

All experiments were carried out in accordance with the National Institutes of Health $(\mathrm{NIH})$ guidelines and approved by the Ethics Committee of the College of Veterinary Medicine, Kyungpook National University, Daegu, Republic of Korea (Permit number: 2017-0014).

\section{Consent for publication}

Not applicable.

\section{Competing interests}

The authors declare that they have no competing interests.

\section{Author details}

'Laboratory of Veterinary Physiology and Cell Signaling, College of Veterinary Medicine, Kyungpook National University, Daegu 41566, Republic of Korea. 2Department of Biomedical Laboratory Science; and Molecular Diagnostics Research Institute, Namseoul University, Cheonan 31020, Republic of Korea. ${ }^{3}$ Department of Clinical Laboratoy Science, Chungbuk Health \& Science University, Cheongju-si, Chungbuk 28150, Republic of Korea. ${ }^{4}$ Department of Animal Biotechnology, Konkuk University, Seoul 05029, South Korea.

Received: 5 November 2019 Accepted: 11 March 2020

Published online: 23 March 2020

\section{References}

1. Gielen S, Landmesser U. The year in cardiology 2013: cardiovascular disease prevention. Eur Heart J. 2014;35(5):307-12.

2. Nichols M, Townsend N, Scarborough P, Rayner M. Cardiovascular disease in Europe: epidemiological update. Eur Heart J. 2013;34(39):3028-34.

3. Shafiq G, Tatinati S, Ang WT, Veluvolu KC. Automatic identification of systolic time intervals in seismocardiogram. Sci Rep. 2016;6:37524.
4. Mozaffarian D, Benjamin EJ, Go AS, Arnett DK, Blaha MJ, Cushman M, Das SR, de Ferranti S, Despres JP, Fullerton HJ, et al. Heart disease and stroke Statistics-2016 update: a report from the American Heart Association. Circulation. 2016;133(4):e38-360.

5. Fuster V, Fayad ZA, Moreno PR, Poon M, Corti R, Badimon JJ. Atherothrombosis and high-risk plaque: part II: approaches by noninvasive computed tomographic/magnetic resonance imaging. J Am Coll Cardiol. 2005;46(7):1209-18.

6. Shin $\mathrm{J}-\mathrm{H}$, Kwon $\mathrm{H}-\mathrm{W}$, Rhee $\mathrm{MH}$, Park $\mathrm{H}$-J. Inhibitory effects of thromboxane A2 generation by ginsenoside Ro due to attenuation of cytosolic phospholipase A2 phosphorylation and arachidonic acid release. J Ginseng Res. 2019:43(2):236-41

7. Barrett NE, Holbrook L, Jones S, Kaiser WJ, Moraes LA, Rana R, Sage T, Stanley RG, Tucker KL, Wright B, et al. Future innovations in anti-platelet therapies. Br J Pharmacol. 2008;154(5):918-39.

8. Rastogi S, Pandey MM, Rawat A. Traditional herbs: a remedy for cardiovascular disorders. Phytomedicine. 2016;23(11):1082-9.

9. Irfan M, Kim M, Rhee MH. Anti-platelet role of Korean ginseng and ginsenosides in cardiovascular diseases. J Ginseng Res. 2020;44(1):24-32.

10. Krasinska B, Osińska A, Osinski M, Krasinska A, Rzymski P, Tykarski A, Krasiński Z. Standardised tomato extract as an alternative to acetylsalicylic acid in patients with primary hypertension and high cardiovascular risk-a randomised, controlled trial. Arch Med Sci. 2018;14(4):773.

11. Poniedziałek B, Siwulski M, Wiater A, Komaniecka I, Komosa A, Gąsecka M, Magdziak Z, Mleczek M, Niedzielski P, Proch J. The effect of mushroom extracts on human platelet and blood coagulation: in vitro screening of eight edible species. Nutrients. 2019;11(12):3040.

12. Kim J-H. Pharmacological and medical applications of Panax ginseng and ginsenosides: a review for use in cardiovascular diseases. J Ginseng Res. 2018:42(3):264-9.

13. Wegiera M, Smolarz HD, Bogucka-Kocka A. Rumex L. species induce apoptosis in 1301, EOL-1 and H-9 cell lines. Acta Pol Pharm. 2012:69(3):487-99.

14. Jeon B-R, Irfan M, Lee SE, Lee JH, Rhee MH. Astilbe chinensis modulates platelet function via impaired MAPK and PLCY2 expression. Evid Based Complement Alternat Med. 2018;2018:8.

15. Kato T, Morita Y. C-glycosylflavones with acetyl substitution from Rumex acetosa L. Chem Pharm Bull. 1990;38(8):2277-80

16. Bae J-Y, Lee YS, Han SY, Jeong EJ, Lee MK, Kong JY, Lee DH, Cho KJ, Lee H$\mathrm{S}$, Ahn M-J. A comparison between water and ethanol extracts of Rumex acetosa for protective effects on gastric ulcers in mice. Biomol Ther. 2012; 20(4):425

17. Bicker J, Petereit F, Hensel A. Proanthocyanidins and a phloroglucinol derivative from Rumex acetosa L. Fitoterapia. 2009;80(8):483-95.

18. Derksen A, Hensel A, Hafezi W, Herrmann F, Schmidt TJ, Ehrhardt C, Ludwig S, Kühn J. 3-O-galloylated procyanidins from Rumex acetosa L. inhibit the attachment of influenza A virus. PLoS One. 2014;9:10.

19. Vasas A, Orbán-Gyapai O, Hohmann J. The genus Rumex: review of traditional uses, phytochemistry and pharmacology. J Ethnopharmacol. 2015:175:198-228.

20. Han S-H, Woo N-R-Y, Lee S-D, Kang M-H. Antioxidaitve and antibacterial activities of endemic plants extracts in Korea. Korean J Med Crop Sci. 2006; 14(1):49-55

21. Qamar HM-U-D, Qayyum R, Salma U, Khan S, Khan T, Shah AJ. Vascular mechanisms underlying the hypotensive effect of Rumex acetosa. Pharm Biol. 2018:56(1):225-34

22. Gescher K, Hensel A, Hafezi W, Derksen A, Kuhn J. Oligomeric proanthocyanidins from Rumex acetosa $L$. inhibit the attachment of herpes simplex virus type-1. Antivir Res. 2011;89(1):9-18.

23. Lee N-J, Choi J-H, Koo B-S, Ryu S-Y, Han Y-H, Lee S-I, Lee D-U. Antimutagenicity and cytotoxicity of the constituents from the aerial parts of <i>Rumex acetosa</i>. Biol Pharm Bull. 2005;28(11):2158-61.

24. Amuamuta A, Plengsuriyakarn T, Na-Bangchang K. Anticholangiocarcinoma activity and toxicity of the Kaempferia galanga Linn. Rhizome ethanolic extract. BMC Complement Altern Med. 2017;17(1):213.

25. Irfan M, Kwon T-H, Yun B-S, Park N-H, Rhee MH. Eisenia bicyclis (brown alga) modulates platelet function and inhibits thrombus formation via impaired P2Y12 receptor signaling pathway. Phytomedicine. 2018:40:79-87.

26. Kim DS, Irfan M, Sung YY, Kim SH, Park SH, Choi YH, Rhee MH, Kim HK Schisandra chinensis and Morus alba synergistically inhibit in vivo Thrombus formation and platelet aggregation by impairing the glycoprotein $\mathrm{Vl}$ pathway. Evid Based Complement Alternat Med. 2017;2017:7839658. 
27. Jeong D, Irfan M, Kim S-D, Kim S, Oh J-H, Park C-K, Kim H-K, Rhee MH. Ginsenoside Rg3-enriched red ginseng extract inhibits platelet activation and in vivo thrombus formation. J Ginseng Res. 2017;41(4):548-55.

28. Schaeffer J, Blaustein MP. Platelet free calcium concentrations measured with fura-2 are influenced by the transmembrane sodium gradient. Cell Calcium. 1989;10(2):101-13.

29. Irfan M, Jeong D, Saba E, Kwon H-W, Shin J-H, Jeon B-R, Kim S, Kim S-D, Lee D$\mathrm{H}$, Nah S-Y. Gintonin modulates platelet function and inhibits thrombus formation via impaired glycoprotein VI signaling. Platelets. 2019;30(5):589-98.

30. Tsuji M, Ezumi Y, Arai M, Takayama H. A novel association of fc receptor gamma-chain with glycoprotein $\mathrm{Vl}$ and their co-expression as a collagen receptor in human platelets. J Biol Chem. 1997;272(38):23528-31.

31. Michelson AD. Antiplatelet therapies for the treatment of cardiovascular disease. Nat Rev Drug Discov. 2010;9(2):154-69.

32. Li Z, Delaney MK, O'Brien KA, Du X. Signaling during platelet adhesion and activation. Arterioscler Thromb Vasc Biol. 2010;30(12):2341-9.

33. Lopez E, Bermejo N, Berna-Erro A, Alonso N, Salido G, Redondo P, Rosado J. Relationship between calcium mobilization and platelet $a$-and $\delta$-granule secretion. A role for TRPC6 in thrombin-evoked $\delta$-granule exocytosis. Arch Biochem Biophys. 2015;585:75-81.

34. Calderwood DA. Integrin activation. J Cell Sci. 2004;117(Pt 5):657-66

35. Adam F, Kauskot A, Nurden P, Sulpice E, Hoylaerts MF, Davis RJ, Rosa JP, Bryckaert M. Platelet JNK1 is involved in secretion and thrombus formation. Blood. 2010;115(20):4083-92.

36. Senis YA, Mazharian A, Mori J. Src family kinases: at the forefront of platelet activation. Blood. 2014;124(13):2013-24.

37. Stöggl WM, Huck CW, Bonn GK. Structural elucidation of catechin and epicatechin in sorrel leaf extracts using liquid-chromatography coupled to diode array-, fluorescence-, and mass spectrometric detection. J Sep Sci. 2004;27(7-8):524-8.

38. Santhakumar AB, Bulmer AC, Singh I. A review of the mechanisms and effectiveness of dietary polyphenols in reducing oxidative stress and thrombotic risk. J Hum Nutr Diet. 2014:27(1):1-21.

\section{Publisher's Note}

Springer Nature remains neutral with regard to jurisdictional claims in published maps and institutional affiliations.

Ready to submit your research? Choose BMC and benefit from:

- fast, convenient online submission

- thorough peer review by experienced researchers in your field

- rapid publication on acceptance

- support for research data, including large and complex data types

- gold Open Access which fosters wider collaboration and increased citations

- maximum visibility for your research: over $100 \mathrm{M}$ website views per year

At $\mathrm{BMC}$, research is always in progress.

Learn more biomedcentral.com/submissions 